\title{
BMJ Open Cohort profile: the Danish Future Occupation of Children and Adolescents cohort (the FOCA cohort): education, work-life, health and living conditions in a life-course perspective
}

\author{
Louise Lindholdt, ${ }^{1,2}$ Thomas Lund, ${ }^{3,4}$ Johan Hviid Andersen, ${ }^{4,5}$ Claus D Hansen, ${ }^{4,6}$ \\ Merete Labriola ${ }^{1,4}$
}

To cite: Lindholdt L, Lund T, Andersen $\mathrm{JH}$, et al. Cohort profile: the Danish Future Occupation of Children and Adolescents cohort (the FOCA cohort): education, work-life, health and living conditions in a life-course perspective. BMJ Open 2019;9:e022784. doi:10.1136/ bmjopen-2018-022784

- Prepublication history for this paper is available online. To view these files, please visit the journal online (http://dx.doi. org/10.1136/bmjopen-2018022784).

JHA and CDH contributed equally.

Received 5 March 2018 Revised 9 November 2018 Accepted 28 November 2018

Check for updates

(c) Author(s) (or their employer(s)) 2019. Re-use permitted under CC BY-NC. No commercial re-use. See rights and permissions. Published by BMJ.

For numbered affiliations see end of article.

Correspondence to Dr Merete Labriola; mela@ph.au.dk

\section{ABSTRACT}

Purpose The Future 0ccupation of Children and Adolescents cohort (the FOCA cohort) is a large populationbased cohort study that was established as a resource for research in order to study adolescence factors and future educational and vocational trajectories in a lifecourse perspective. The cohort covers a broad array of themes within public health, including diseases and health behaviours. Through linkage to register data on the participants' parents, the cohort allows investigation of parental effects over time on adolescents' behaviours and interactions across generations.

Participants The FOCA cohort consists of 13100 adolescents attending ninth grade in Denmark during the first quarter of 2017, independent of school type.

Findings to date Included were 6685 girls $(51.03 \%)$ and 6415 boys $(48.97 \%)$ with an average age of 15.85 years, representing 650 schools (37.23\%), covering all options in the Danish school system and widely distributed across the country. The use of the personal identification number allowed for a merge of parents to all adolescents in the cohort, resulting in the identification of 25911 registered parents. Register data on parents' socio-economic position and labour market history showed representativeness among the adolescents' socio-economic background compared with the general population in Denmark. Future plans The adolescents will be followed by ongoing linkage to administrative registers. Future studies will focus on factors affecting future health, education, work and well-being in a life-course perspective and for specific research projects, it will be possible to apply for permission to link data to further ongoing national registers covering all participants.

\section{INTRODUCTION}

Getting caught in the transition from lower to upper secondary education or vocational education can cause educational, and even working life, to end before it begins for many adolescents. According to the Organisation for Economic Co-operation and Development (OECD), $20 \%$ of young people end

\section{Strengths and limitations of this study}

- The Future Occupation of Children and Adolescents cohort (the FOCA cohort) consists of a large population-based sample of adolescents attending ninth grade independent of school type, based on all options in the Danish school system, which is a unique feature for this type of survey.

- The main strength of the cohort is the possibility of merging the register data of respondents and their parents, enabling studies of effects of parental factors on child health and status in the broadest of terms and encompassing a life-course perspective on childhood factors and future educational and vocational trajectories.

- The FOCA cohort provides unique opportunities for studies of adolescents' health and work-life and, due to shared items on childhood adversities, subjective health complaints and health behaviour with the Norwegian Young-HUNT study, the FOCA cohort can accommodate future cross-national comparative studies on effects of mental well-being and functioning, subjective health and health behaviour on educational and vocational trajectories between the two countries.

- The FOCA questionnaire contains 400 items which require some basic reading skills. Therefore, it cannot be ruled out that adolescents with reading difficulties or poor Danish language skills are under-represented in this cohort.

their educational pathway before reaching upper secondary level, with potentially negative consequences for both the individual and society. ${ }^{1-3}$ Dropping out, and thus having a lower level of education, has important consequences for the young adults later in life. Early socio-economic inequalities in adolescents' health predict future inequalities in adult health. ${ }^{4}$ These young people are at greater risk of developing health and social problems 
that serve as a barrier to secondary education and stable employment. Studies have established that both health as well as social problems in youth and adolescence predict weak labour market participation later in life and largely constitute a major public health problem. ${ }^{5-9}$

In Denmark there has been a $50 \%$ increase in the number of young people who received social benefits, from 61000 in 2007 to 92000 in 2012. ${ }^{10}$ Compared with other EU and OECD countries, the proportion of people obtaining an education is generally above average. However, there has been an increase in young people with a poor integration into education: the proportion of people aged 25-34 years having below secondary education in Denmark increased from $13 \%$ to $16 \%$ in the period from 2000 to 2016, with the EU average being 15\% in $2016 .{ }^{11}$ National figures show that $31 \%$ of the 25 -yearolds had not completed an upper secondary education in $2014 .{ }^{12}$ In order to study the transition from lower and upper secondary education into a stable position on the labour market, longitudinal studies are needed. Apparently, there is a lack of longitudinal studies that makes it possible to investigate how health, social issues and lifestyle in combination with well-being are affected by educational attainment and labour market participation across the life-course. ${ }^{2}$

The purpose of the Future Occupation of Children and Adolescents cohort (the FOCA cohort) was to launch a longitudinal study to: (1) study the impact of different exposures in relation to integration into education and employment, (2) to cover public health issues, including diseases and health behaviours tracked over a life-course, (3) to study parental effects over time on adolescents' behaviours and (4) to study social inheritance across generations.

\section{COHORT DESCRIPTION}

The FOCA cohort is a longitudinal cohort study inviting all eligible adolescents attending the ninth grade in 1746 schools, independent of school type, in Denmark. With the purpose of recruiting as many adolescents as possible, as well as getting a representative group, the schools were chosen as the main setting for recruiting the adolescents. An extraction of institutions from the National Agency for IT and Learning at the Ministry of Education identified 2618 potential schools to be considered. An initial review of the extraction excluded 379 schools due to not having ninth grade.

Thus, 2239 schools were screened for participation in the FOCA cohort, excluding an additional 493 schools. Of these 255 were special schools and treatment centres who deemed their adolescents incapable of answering the questionnaire due to cognitive challenges, low levels of abstraction, multiple handicaps, severe reading and writing difficulties and other mental or social challenges. The remaining excluded schools were found not having ninth grade despite being included in the original data extraction. This entailed 1746 eligible schools, which were contacted and invited to participate. Of these, 650 schools agreed to participate and were included in the final cohort with a total of 13100 adolescents from different school-types based on all options in the Danish school system (figure 1).

\section{Invitation procedure}

The secretariats and the headmasters of the schools received an email invitation from the survey staff containing information about the survey, a brief instruction about the questionnaire, and a hyperlink enabling them to register their school for participation in the survey. The intention was that the information about the survey should reach the responsible teachers for ninth grade who subsequently communicated it to the pupils. Besides the written information, the survey staff attempted to contact the headmasters of all the eligible schools by phone during the recruitment process. The schools were advised to allocate a lesson during regular school hours, allowing the pupils to answer the questionnaire in class, with the purpose of improving their engagement in filling out the questionnaire.

Schools unable to allocate a lesson to fill out the questionnaire were encouraged to inform about the survey on their intranet to provide the pupils with the opportunity to read about the survey and access the questionnaire. In addition, information about the survey was distributed through professional organisations, periodicals and social media.

The questionnaire was digital and the pupils gained access through their personal Uni-login. This is a digital identification number linked to the specific educational institution, given to all pupils in Denmark by the National Agency for IT and Learning. It was voluntary for the pupils to answer the questionnaire and they had the right to withdraw their participation at any time. All the answers were treated as strictly confidential, and the pupils were guaranteed full anonymity.

\section{Data collection}

Data were collected through a self-reported questionnaire, the FOCA questionnaire, during the first quarter of 2017. The FOCA questionnaire was developed and pretested during 2015-2016 and consisted of 100 questions totalling 400 items capturing sociological, psychological and health-related components of importance for future educational and work life trajectories. ${ }^{13}$ The questionnaire was constructed to cover seven overarching themes: (1) peer context, (2) living conditions, (3) school context and education, (4) family context, (5) health and well-being, (6) psychosocial factors and (7) health behaviour (table 1). Outside these overarching themes, the questionnaire contained questions about school type, relationships, self-efficacy and personality.

The questions included in the FOCA questionnaire were derived from various sources. Some of the questions were validated scales and items adopted and translated from other existing surveys like Health Behaviour in 


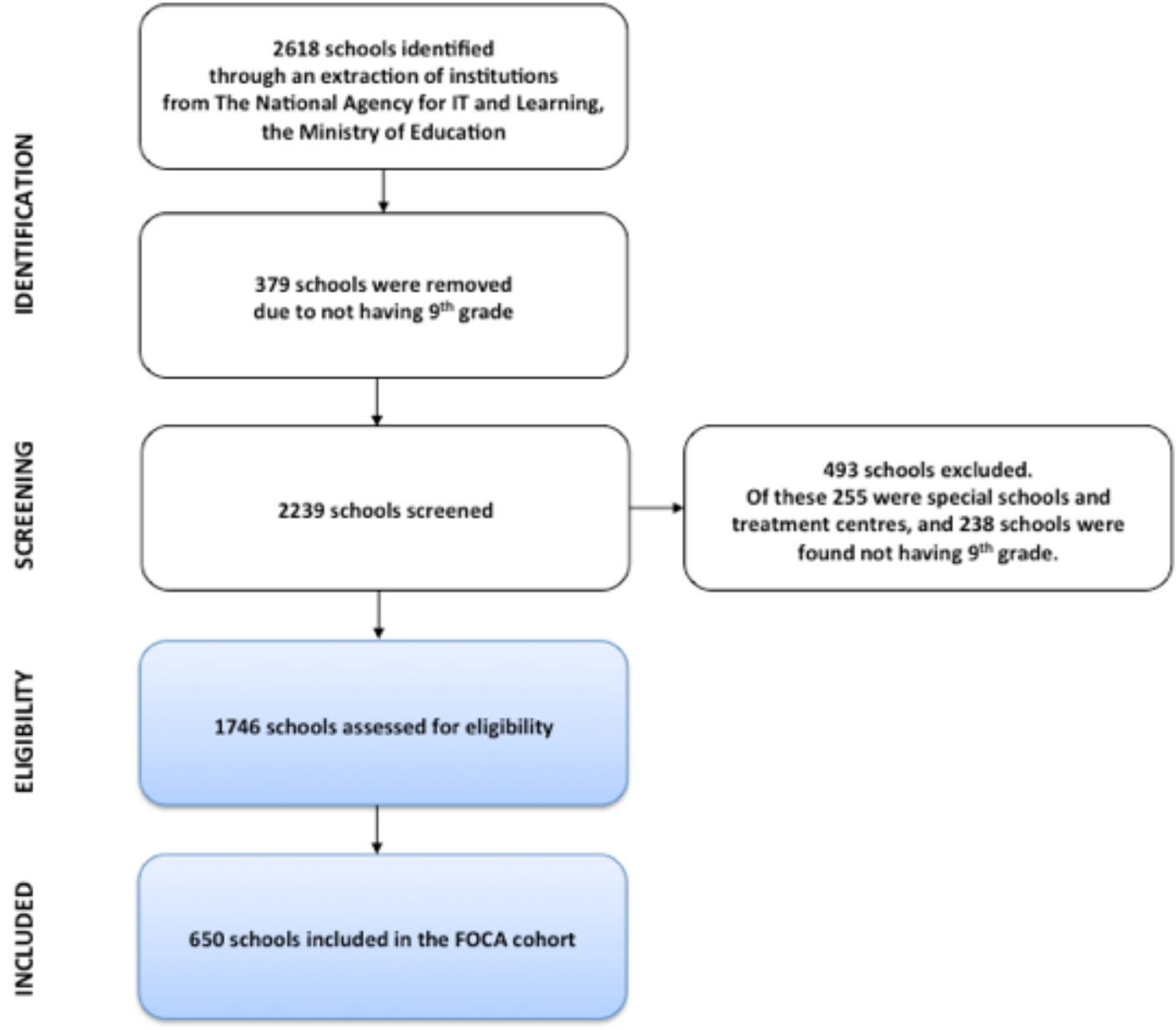

Figure 1 Flowchart of schools included in the Future Occupation of Children and Adolescents (FOCA) cohort.

School-Aged Children (HBSC) ${ }^{1415}$ and the Young-HUNT study. ${ }^{16}$ Additionally, some of the questions were devised specifically for the FOCA questionnaire (table 1$).^{13}$
To ensure that the questionnaire worked for the target group, the questionnaire was pretested by allowing a representative sample of pupils to answer it. The pupils

\begin{tabular}{ll}
\hline Table 1 Overview of contents of the Future Occupation of Children and Adolescents questionnaire \\
\hline Topic & Contents \\
\hline School & School type. \\
Relationships & Relationships. \\
Peer context & Social relations, leisure time activities, gaming, loneliness. \\
Living conditions & $\begin{array}{l}\text { Upbringing, home characteristics, neighbourhood, deprivation, after-school job, subjective } \\
\text { socio-economic status. }\end{array}$ \\
School context and education & $\begin{array}{l}\text { Demands/pressure, control, reading difficulties, homework, homework support, teacher } \\
\text { support, classmate support/integration, absenteeism, school satisfaction, IT, educational } \\
\text { plans/future aspirations. }\end{array}$ \\
Family context & Family functioning, parental style, curfew. \\
Health and well-being & $\begin{array}{l}\text { Self-rated health, life satisfaction, mental health, Strengths and Difficulties Questionnaire, } \\
\text { body shape, pain, medicine, perceived stress, externalising reactions. }\end{array}$ \\
Psychosocial factors & Meaningfulness, self-esteem, coping, childhood events, accidents. \\
\hline Health behaviour & Physical activity, alcohol, smoking, hash, illegal drugs, snuff. \\
Self-confidence & Self-efficacy. \\
Personality & Personality assessment. \\
\hline
\end{tabular}


were then interviewed to evaluate in advance whether the questionnaire was perceived as meaningful, difficult, sensitive or caused problems for the pupils. Furthermore, the interview aimed to identify the pupils' opinion on the questionnaire's applicability, comprehensibility and completeness. The pupils were asked a series of questions regarding the questionnaire as well as their experience with completing it, covering elements such as problems with the format, design, the inability to answer some of the questions and opinions on potentially sensitive questions. Based on the pretest results, some questions were discussed in the research team, where collaborative decisions were made regarding the necessity of changes in the questionnaire. On this basis, a consensus questionnaire was constructed, which was pilot-tested on a new sample of pupils mirroring the target group, before the final data collection.

\section{Linkage of data}

All data from the FOCA cohort are linked to the unique personal identification number (the CPR-number) assigned to every Danish citizen at birth. ${ }^{17}$ This makes it possible to identify the adolescents' parents using the CPR-number through The Fertility Database of Statistics, Statistics Denmark, which, based on the administrative data, contains information on the relation between the adolescents and their parents. Furthermore, the use of CPR-numbers makes it possible to link data between the FOCA cohort survey and other surveys and also link the cohort data of each participant to national registers on education through the Danish Educational Register and labour market attachment through the Danish Register of Evaluation of Marginalization with very little data missing. The adolescents will be followed up by ongoing linkages to administrative registers, meaning that no questionnaire-based follow-up is planned. The first register-based follow-up on educational attainment, labour market participation as well as information on dropout from education will commence in 2018, where information from 2017 will become available. These data will be updated annually.

In addition, the data have been linked to register data on parents' socio-economic position in terms of highest education, household income and labour market participation. This yields the possibility of studying the effects of factors in a life-course perspective and give the unique possibility of studying parental effects over time on adolescents' behaviours and to environmental interactions across generations.

Furthermore, for specific research projects, it will be possible to apply for permission to link data to further ongoing national registers covering all participants, like the Cancer Register, Causes of Death Register, Pescription Register, Income and Tax Register and Hospital Disease register.

\section{Patient and public involvement}

No patients were involved in the study.
Table 2 Sex, age, school type and residence

n (\%) or mean (SD)

\begin{tabular}{|ll}
\hline Sex & $6685(51.03)$ \\
\hline Girls (\%) & $6415(48.97)$ \\
\hline Boys (\%) & $15.85(0.43)$ \\
\hline Age (mean (SD)) & \\
\hline School type & $10332(78.87)$ \\
\hline $\begin{array}{l}\text { Compulsory school (municipal) (\%) } \\
\text { Compulsory school (private) (\%) }\end{array}$ & $1290(9.85)$ \\
\hline $\begin{array}{l}\text { Compulsory school (continuation } \\
\text { school) (\%) }\end{array}$ & $1168(8.91)$ \\
\hline $\begin{array}{l}\text { Compulsory school (special school) } \\
\text { (\%) }\end{array}$ & $310(2.37)$ \\
\hline Residence & \\
\hline North Denmark Region (\%) & $1186(9.05)$ \\
\hline $\begin{array}{l}\text { Central Denmark Region (\%) } \\
\text { Region of Southern Denmark (\%) }\end{array}$ & $3650(27.86)$ \\
\hline $\begin{array}{l}\text { Region Zealand (\%) } \\
\text { Capital Region of Denmark (\%) }\end{array}$ & $2034(15.53)$ \\
\hline
\end{tabular}

\section{FINDINGS TO DATE}

A total of 13100 adolescents attending ninth grade from different school-types participated in the FOCA cohort. Adolescents attending municipal schools, private schools, continuation schools and special schools were represented, with a majority attending municipal schools (table 2). This corresponded to 650 schools being represented $(37.23 \%)$, widely distributed across the country. Included were 6685 girls $(51.03 \%)$ and 6415 boys $(48.97 \%)$ with an average age of 15.85 years.

A linkage to the Fertility Database identified 25911 registered parents. To investigate the adolescents' socio-economic background and whether the cohort was representative in that respect, register data were obtained containing parents' socio-economic status in terms of highest level of education and labour market participation.

Educational level was classified into 10 categories based on the highest level of completed education among the parents. These data were compared with the level of education among the general population in Denmark within the same-age categories as the parents of the adolescents in the FOCA cohort. ${ }^{18}$ The comparison showed that the level of education among the parents was almost identical to the level of education among the general population when comparing the 10 categories of highest level of education (figure 2). The biggest difference appeared with the fraction that had primary and lower secondary education as their highest level of education, with $14.8 \%$ of the parents compared with $19.9 \%$ in the general population. Likewise, a difference appeared in the fraction where vocational education was registered as the highest level of education, with $40.6 \%$ of the 


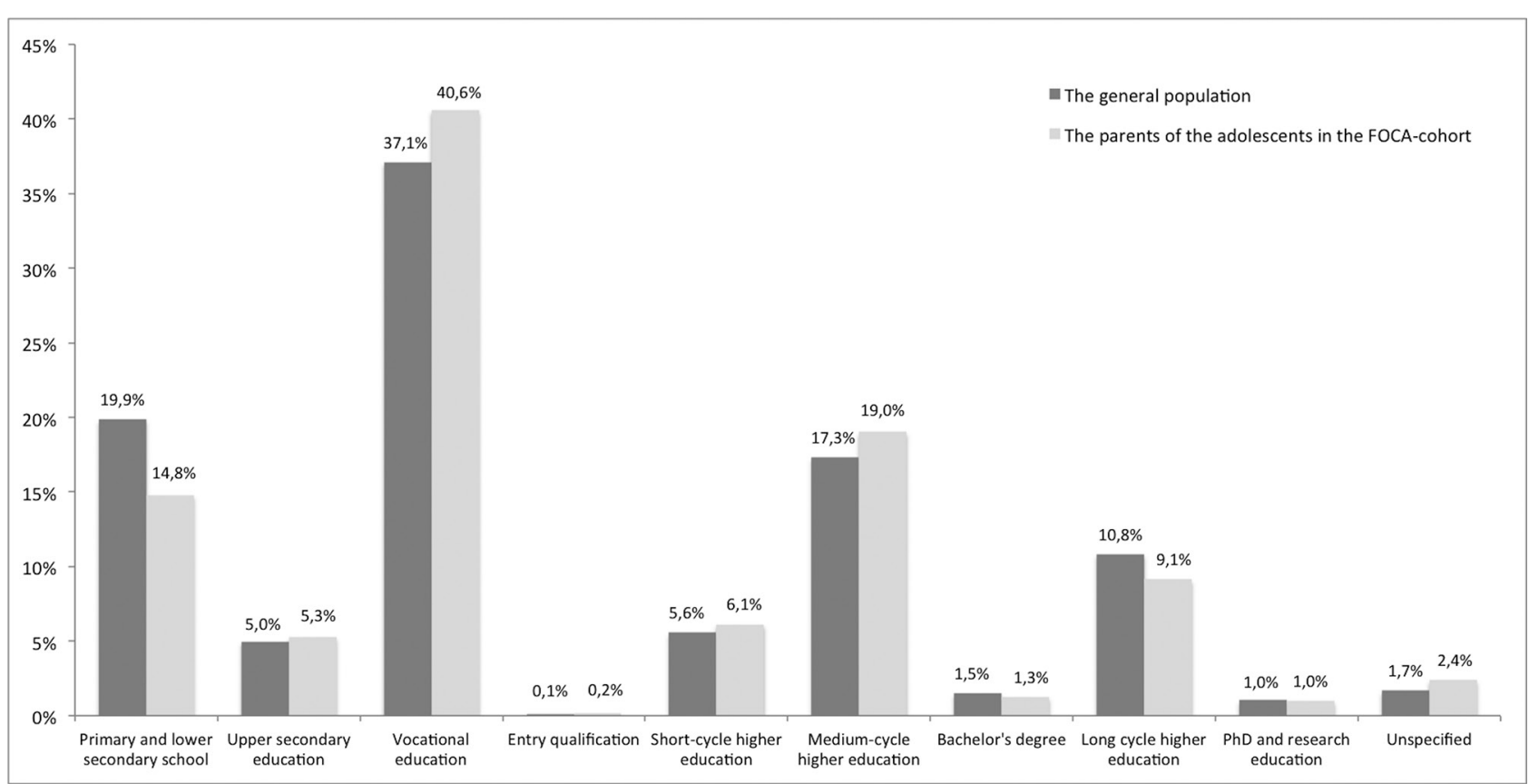

Figure 2 Parental level of education. FOCA, Future Occupation of Children and Adolescents.

parents compared with $37.1 \%$ in the general population. Looking at the remaining eight categories of education, only minor differences appeared.

With regard to labour market participation, parents were divided into those in paid employment at the time when their child/children filled out the questionnaire and those outside the labour market. They were compared with the labour market participation rate among the general population in Denmark within the same age-categories as the parents of the adolescents in the FOCA cohort. ${ }^{19}$ The comparison showed that $82.6 \%$ of the fathers of the FOCA participants were in paid employment, while the figure was $80.5 \%$ among the general male population. For the mothers of the participants, the corresponding figures were $76.6 \%$ and $74.3 \%$.

In addition to the characteristics of the study population and findings related to their socio-economic background based on their parents' labour market participation and highest attained education, a Danish report summarising the frequencies of responses to the items in the baseline questionnaire was published. The report showed frequencies of missing values ranging from $1.43 \%$ to $20.09 \%$ measured on single items, with increasing frequency of missing values towards the end of the questionnaire.

\section{Future plans}

The FOCA cohort will provide state-of-the-art evidence base for actors, stakeholders and decision-makers within youth, health, education and occupation, both at policy and practice levels. Future projects will focus on the following themes:

1. Frequency and distribution of peer context, living conditions, school context and education, family context, health and well-being, psychosocial factors, health behaviour, relationships, self-efficacy and personality among adolescents in Denmark and their relation to future dropout from education, marginalisation from work, and poor health and well-being.

2. Effects of factors related to the parents (eg, parenting style, socio-demographic position) over time on adolescents' behaviours and environmental interactions across generations.

3. Development of valid and relevant measures to assess trajectories over time between social transfer payments, education and work in order to identify typical pathways between in and out of education and work among young people.

4. Development of tools to identify high-risk profiles with excess risk of future educational dropout, labour market marginalisation, poor health and well-being.

5. Ongoing monitoring of health, well-being, vocational education and occupation.

6. Cross-national comparative studies of effects of health, childhood adversities, well-being and health behaviour on educational attainment and labour market participation between adolescents in Norway and Denmark.

7. Feed relevant, high quality evidence into intervention projects focusing on youth, education and occupation.

\section{Strengths and limitations}

It is a strength that the database consists of a large population-based sample of adolescents attending ninth grade in Denmark. Respondents represent municipal schools, private schools, continuation schools and special schools, based on all options in the Danish school system, which is a unique feature for this type of survey in Denmark. Respondents represent 97 of the 98 municipalities in Denmark and preliminary results suggest representativeness across socio-economic strata. The FOCA cohort has support from the formal organisations of pupils, teachers, 
school headmasters and the municipal supervisors of education, the Danish Ministry of Education and the Danish Ministry of Employment.

In general, a high proportion of the baseline questionnaire was filled out by the respondents, but the main strength of the study is the possibility of merging with register data on respondents and their parents, enabling studies of effects of parental factors on child health and status in the broadest of terms and encompassing a life-course perspective on childhood factors and future educational and vocational trajectories. Futheremore, the FOCA questionnaire survey, shares certain items with the Young-HUNT study in Norway, ${ }^{16}$ including the Strengths and Difficulties Questionnaire,$^{20}$ childhood adversities, subjective health complaints and items covering aspects of health behaviour (smoking, alcohol consumption, substance abuse and physical activity). This will enable future comparative studies of effects of mental well-being and functioning, subjective health and health behaviour on educational and vocational trajectories between the two countries.

A weakness is that it was not possible to report an overall response rate due to the sampling procedure used in recruiting potential respondents at the school level. According to Statistics Denmark, a total of 68557 adolescents were registered as attending the ninth grade in the school year 2016/2017. It was not possible to identify the exact number of pupils, who were excluded during the review and screening process, and not possible to identify the actual size of the target population, since it was not possible to identify or obtain information on the exact number of pupils in every school at the time of data collection.

An additional weakness is the fact that the 400-item questionnaire requires some basic reading skills. Despite efforts from the FOCA staff to enhance participation among those with literary challenges (for example personal visits and support to special schools during class level response sessions), it cannot be ruled out that adolescents with reading difficulties or poor Danish language skills are under-represented. This is manifested by the fact that the special schools attended by adolescents with severe literary challenges are relatively under-represented in the dataset compared with the other school types. This could potentially cause underestimation of certain health-related and socially determined adversities.

\section{Author affiliations}

${ }^{1}$ Department of Public Health, University of Aarhus, Aarhus, Denmark

${ }^{2}$ DEFACTUM, Central Denmark Region, Aarhus, Denmark

${ }^{3}$ Centre for Social Medicine, Frederiksberg and Bispebjerg Hospital, Copenhagen, Denmark

${ }^{4}$ Research Centre for Youth and Employment, Regional Hospital West Jutland, University Research Clinic, Herning, Denmark

${ }^{5}$ Department of Occupational Medicine, Danish Ramazzini Centre, Regional Hospital West Jutland, University Research Clinic, Herning, Denmark

${ }^{6}$ Department of Sociology and Social Work, Aalborg University, Aalborg, Denmark

Acknowledgements The authors wish to thank Lea Billeskov, Lina El-Sarih, Mette-Marie Zacher Kjeldsen, Mathilde Hyldahl Dieckmann, Ida Ejdrup Larsen,
Nanna Husted Jensen, and Søren Sander from DEFACTUM, Central Denmark Region, Elisabeth Dørken form Dept. of Occupational Medicine at Regional Hospital Herning and Mariann Bach Nielsen from "2vejs kommunikation" for their valuable efforts in recruiting respondents, data collection and communication, and the 13 100 pupils who gave their time to complete the FOCA survey.

Collaborators The FOCA cohort is administrated by Research Centre for Youth and Employment, Herning, Denmark, a multicentre research initiative across four organisations encompassing expertise from several academic disciplines including occupational and social epidemiology, sociology, psychology and public health. The FOCA cohort database is available for all researchers affiliated to a qualified research institution. Agreements are drawn up between the institution and the scientific committee of FOCA, who administer the database and coordinate research based upon The FOCA cohort. Applications are to be sent to FOCA and each project also needs to be approved by the Danish Data Protection Agency and Statistics Denmark. Enquiries may be directed to: Merete Labriola at mela@ph. au.dk, Thomas Lund at Thomas.Lund.01@regionh.dk, Louise Lindholdt at louise. lindholdt@ph.au.dk or Claus D. Hansen at clausdh@socsci.aau.dk.

Contributors LL, TL, ML, JHA and CDH conceived the idea for the establishing cohort, and contributed to construction of the questionnaire. ML headed the data collection. $\mathrm{LL}$ and TL contributed to the data collection process. LL performed all data management and descriptive analyses. LL wrote the first draft for the manuscript. ML and TL contributed to the first draft. All authors supplied with valuable input to the final version of the manuscript, which has been approved by all authors.

Funding The design of the study began in 2012 and the first grant was given to the project to cover operational expenses from The Ministry of Employment Denmark in 2014 (no grant number available), whereas payroll funds were given from The Danish Working Environment Research Fund in 2014 project no. 20140073389.

Competing interests None declared.

Patient consent for publication Not required.

Ethics approval The FOCA cohort is approved by the Danish Data Protection Agency, approval no. 1-16-02-461-16 and the Ethics Committee of Statistics, Denmark and complies with national legislation for use of data for research. Voluntary participation was highlighted.

Provenance and peer review Not commissioned; externally peer reviewed.

Data sharing statement The FOCA cohort database is available for all researchers affiliated to a qualified research institution. Agreements are drawn up between the institution and the scientific committee of FOCA, who administer the database and coordinate research based upon The FOCA cohort. Applications are to be sent to FOCA and each project also needs to be approved by the Danish Data Protection Agency and Statistics Denmark. Enquiries may be directed to: Merete Labriola at mela@ph.au.dk, Thomas Lund at Thomas.Lund.01@regionh.dk, Louise Lindholdt at louise.lindholdt@ph.au.dk or Claus D. Hansen at clausdh@socsci.aau.dk

Open access This is an open access article distributed in accordance with the Creative Commons Attribution Non Commercial (CC BY-NC 4.0) license, which permits others to distribute, remix, adapt, build upon this work non-commercially, and license their derivative works on different terms, provided the original work is properly cited, appropriate credit is given, any changes made indicated, and the use is non-commercial. See: http://creativecommons.org/licenses/by-nc/4.0/.

\section{REFERENCES}

1. OECD. Equity and quality in Education: Supporting disadvantaged students and Schools. Paris: OECD Publishing, 2012.

2. Eslami Z, Walters L. Understanding why students drop out of high school, according to their own reports: are they pushed or pulled, or do they fall out? A comparative analysis of seven nationally representative studies. SAGE Open 2013;15:1.

3. Patel V, Flisher AJ, Hetrick S, et al. Mental health of young people: a global public-health challenge. Lancet 2007;369:1302-13.

4. Elgar FJ, Pförtner T-K, Moor I, et al. Socioeconomic inequalities in adolescent health 2002-2010: a time-series analysis of 34 countries participating in the Health Behaviour in School-aged Children study. The Lancet 2015;385:2088-95.

5. Ose SO, Jensen C. Youth outside the labour force - Perceived barriers by service providers and service users: A mixed method approach. Child Youth Serv Rev 2017;81:148-56. 
6. Ahlborg M, Svedberg P, Nyholm M, et al. Socioeconomic inequalities in health among Swedish adolescents - adding the subjective perspective. BMC Public Health 2017;17:838.

7. Winding TN, Labriola M, Nohr EA, et al. The experience of demanding work environments in younger workers. Occup Med 2015;65:324-30.

8. De Ridder KA, Pape K, Cuypers K, et al. High school dropout and long-term sickness and disability in young adulthood: a prospective propensity score stratified cohort study (the Young-HUNT study). BMC Public Health 2013;13:941.

9. Hogan DP, Astone NM. The transition to adulthood. Annu Rev Sociol 1986;12:109-30.

10. Statistics Denmark. http://www.dst.dk/da/Statistik/Publikationer/ VisPub?cid=17951 (Accessed 8. Dec. 2017).

11. OECD. Education at a Glance 2017: OECD Indicators. Paris: OECD Publishing, 2017.

12. Statistics Denmark. http://www.dst.dk/da/statistik/nyt/NytHtml?cid= 19298 (Accessed 6 Dec 2017).

13. The FOCA website. Accessed 8 Dec 2017 http://foca.dk/userfiles/ file/FOCA\%20ENG_Dokumentationsrapport_december2017(1).pdf.

14. The HBSC website. http://www.hbsc.org (Accessed 8. Dec. 2017).
15. Currie C, Zanotti C, Morgan A, et al. Social determinants of health and well-being among young people. Health Behaviour in Schoolaged Children (HBSC) study: international report from the 2009/2010 survey. København: WHO Regional Office for Europe. 2012 Health Policy for Children and Adolescents, No. 6.

16. Holmen TL, Bratberg G, Krokstad S, et al. Cohort profile of the Young-HUNT Study, Norway: a population-based study of adolescents. Int J Epidemiol 2014;43:536-44.

17. Pedersen CB. The Danish Civil Registration System. Scand J Public Health 2011;39(Suppl):22-5.

18. Statistics Denmark. HFUDD10: population highest full education education (15-69 years) after building area, arrival, highest full education education, every and knee. Accessed 6. Dec. 2017 http://www.statistikbanken.dk/statbank5a/selectvarval/define.asp? PLanguage $=0$ \&subword=tabsel\&MainTable=HFUDD10\&PXSId $=$ 189211\&tablestyle $=\& S T=S D \&$ buttons $=0$.

19. Statistics Denmark. kneeAKU120: employment marketing (procent) after employment status, every and knee. Accessed 6. Dec. 2017 http://www.statistikbanken.dk/AKU120.

20. Goodman R. The strengths and difficulties questionnaire: a research note. J Child Psychol Psychiatry 1997;38:581-6. 